\section{Best Reviewer Award 2010}

\section{Professor Petru Budrugeac}

(C) Akadémiai Kiadó, Budapest, Hungary 2012

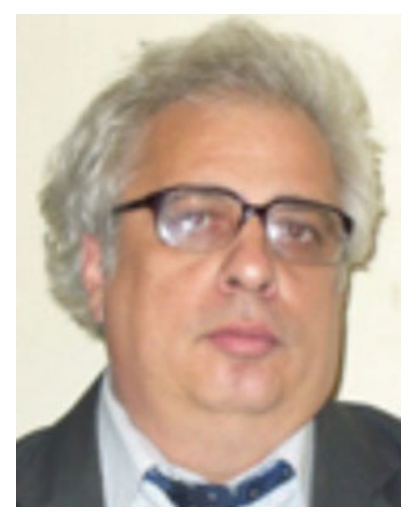

Recently, one of the main driving forces of scientific communities is the continuously increasing pressure for publication, which results in a proportional increase in the number of submitted papers. This tendency is worldwide and most journals have difficulties to find reliable and available reviewers. The limited number of relevant referees might result in an extended peer-reviewing procedure. We have to notice here, that the scientific quality of a journal depends strongly on the quality of the referees, since they are the main filters of the submitted manuscripts. That is the reason why the high-quality and reliable peerreviewers are essential to a scientific journal. Despite of their importance, however, the referees are volunteers and do their job without any financial compensation. Thus, our Journal has decided to give the Best Reviewer Award to our outstanding referees in order to express our indebtedness for their valuable contribution.

Last year was the first time when this Award was delivered to a referee at the CEEC-TAC1 conference in
Craiova, Romania. The first winner is Prof. Petru Budrugeac who works for our Journal as a reviewer and an author as well for a long time. Moreover, he is one of our Associate Editors in the field of kinetic studies.

Prof. Budrugeac was born in 1949 at Carasebes in Romania and has been working as an Associate Professor at Faculty of Chemistry at University of Bucharest since 2003. His is interested in several fields of kinetics, like isothermal and non-isothermal heterogeneous kinetics, thermal analysis of polymers, evaluation of the thermal lifetime of polymeric materials, thermal degradation of patrimonial leathers, parchments and woods and, last but not least, adsorption and catalysis. He has more than 150 publications which are highly cited (Hirsch index $=17$ ). Prof. Budrugeac is the president of the Commission of Thermal Analysis and Calorimetry of the Romanian Academy of Sciences and he is the member of the Romanian Association of Materials. He has accepted more than 40 assignments since 2009, when the EM system was introduced to our Journal. His average reviewing time is 9 days per manuscript, which is extremely short and the reports submitted by him are substantial and help perfectly the decision of the Editors. The rejection rate based on his reviews is $\sim 40 \%$, which value fits to the general rejection rate of the Journal of Thermal Analysis and Calorimetry. This Award expresses our special gratitude to him. We wish him good health and we count on his work in the future as well.

Finally, the team of the Journal of Thermal Analysis and Calorimetry would like to thank the enthusiastic work of the peer-reviewers from all over the world. We hope that we will be able to keep the high scientific level in the future with their support. 